\title{
Selective Activation of Ipsilateral Motor Pathways in Intact Humans
}

\author{
Toshiki Tazoe and Monica A. Perez \\ Department of Physical Medicine and Rehabilitation, Center for the Neural Basis of Cognition, Systems Neuroscience Institute, University of Pittsburgh, \\ Pittsburgh, Pennsylvania 15261
}

It has been proposed that ipsilateral motor pathways play a role in the control of ipsilateral movements and recovery of function after injury. However, the extent to which ipsilateral motor pathways are engaged in voluntary activity in intact humans remains largely unknown. Using transcranial magnetic stimulation over the arm representation of the primary motor cortex, we examined ipsilateral motor-evoked potentials (iMEPs) in a proximal arm muscle during increasing levels of unilateral and bilateral isometric force in a sitting position. We demonstrate that iMEP area and amplitude decreased during bilateral contraction of homonymous (elbow flexor) muscles and increased during bilateral contraction of heteronymous (elbow flexor and extensor) muscles compared with a unilateral contraction, regardless of the level of force tested. To further understand the neuronal inputs involved in the bilateral effects, we examined the contribution from neck afferents projecting onto ipsilateral motor pathways. Medial (away from the muscle tested) and lateral (toward the muscle tested) rotation of the head enhanced bilateral iMEP effects from homonymous and heteronymous muscles, respectively. In contrast, head flexion and extension exerted nonspecific bilateral effects on iMEPs. Intracortical inhibition, in the motor cortex where iMEPs originated, showed modulation compatible with the changes in iMEPs. We conclude that ipsilateral projections to proximal arm muscles can be selectively modulated by voluntary contraction of contralateral arm muscles, likely involving circuits mediating asymmetric tonic neck reflexes acting, at least in part, at the cortical level. The pattern of bilateral actions may represent a strategy to engage ipsilateral motor pathways in a motor behavior.

Key words: ipsilateral pathways; motor recovery; primary motor cortex; spinal cord injury; transcallosal pathways; voluntary movement

\section{Introduction}

Ipsilateral motor pathways might contribute to the control of ipsilateral movements (Jankowska and Edgley, 2006). In animals, anatomical and physiological studies showed that a fraction of corticospinal neurons descend ipsilaterally (Armand and Kuypers, 1980; Rosenzweig et al., 2009; Soteropoulos et al., 2011) and some relay on reticulospinal neurons (Stecina and Jankowska, 2007), which in turn converge onto propriospinal neurons (Brinkman and Kuypers, 1973; Alstermark et al., 1984), all terminating in the spinal cord. Because these pathways access limb motoneurons, it has been argued that they might provide an important substrate for motor recovery (Netz et al., 1997; Thuret et al., 2006; BrusRamer et al., 2007; Bradnam et al., 2013).

In humans, transcranial magnetic stimulation (TMS) was used to demonstrate ipsilateral motor-evoked potentials (iMEPs)

\footnotetext{
Received April 23, 2014; revised Aug. 28, 2014; accepted Sept. 2, 2014.

Author contributions: T.T. and M.A.P. designed research; T.T. and M.A.P. performed research; T.T. and M.A.P. contributed unpublished reagents/analytic tools; T.T. and M.A.P. analyzed data; T.T. and M.A.P. wrote the paper.

This work was supported by the National Institute of Neurological Disorders and Stroke-National Institutes of Health (Grant R01 NS076589), the Department of Veterans Affairs (Grant 3397626), and the Paralyzed Veterans of America (Grant 2955).

The authors declare no competing financial interests.

Correspondence should be addressed to Monica A. Perez, PhD, Department of Physical Medicine and Rehabilitation, Center for the Neural Basis of Cognition Systems Neuroscience Institute, University of Pittsburgh, Pittsburgh, PA 15261. E-mail: perezmo@pitt.edu.

DOI:10.1523/JNEUROSCI.1648-14.2014

Copyright $\odot 2014$ the authors $\quad 0270-6474 / 14 / 3313924-11 \$ 15.00 / 0$
}

in upper-limb muscles in intact adults (Wassermann et al., 1991, 1994; Ziemann et al., 1999; Bawa et al., 2004) and in individuals with congenital disorders (Farmer et al., 1990, 1991; Mayston et al., 1997) or agenesis of the corpus callosum (Ziemann et al., 1999). iMEPs likely involve corticoreticulopropriospinal pathways (Ziemann et al., 1999), are commonly present in proximal arm muscles, and typically have higher thresholds and longer latencies, and are elicited from a different cortical location than contralateral MEPs (cMEPs). Although the size of iMEPs in proximal arm muscles can be modulated by inputs from neck afferents (Ziemann et al., 1999), after a sustained isometric voluntary contraction (Bawa et al., 2004), and by noninvasive brain stimulation (Bradnam et al., 2010a,b), the extent to which iMEPs are involved in voluntary activity in intact humans remains unclear.

The bilateral organization of motor pathways controlling ipsilateral proximal arm muscles (Davidson et al., 2007) might allow some predictions. For example, iMEPs present in elbow flexor muscles during a unilateral contraction (Ziemann et al., 1999) are difficult to observe during bilateral tonic contraction of homonymous elbow flexor muscles (Bawa et al., 2004), while peaks of facilitation have been reported in the ipsilateral limb during bilateral contractions of heteronymous elbow flexor and extensor muscles (Perez et al., 2014). Moreover, other neuronal pathways contributing to control ipsilateral muscles (i.e., transcallosal pathway) showed increased inhibition during bilateral activation of homonymous compared with heteronymous mus- 

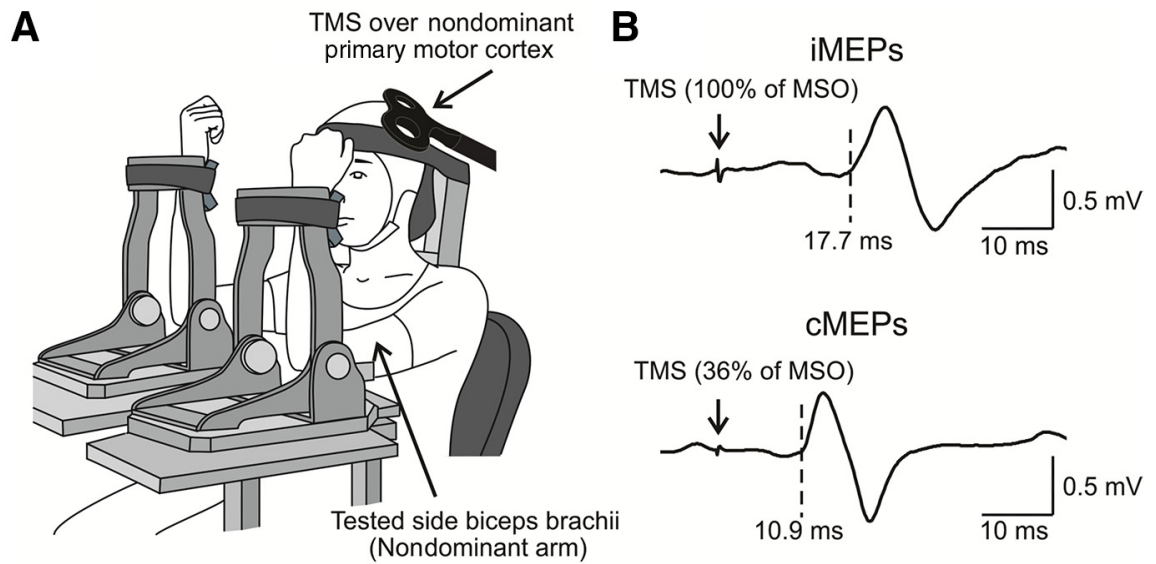

C
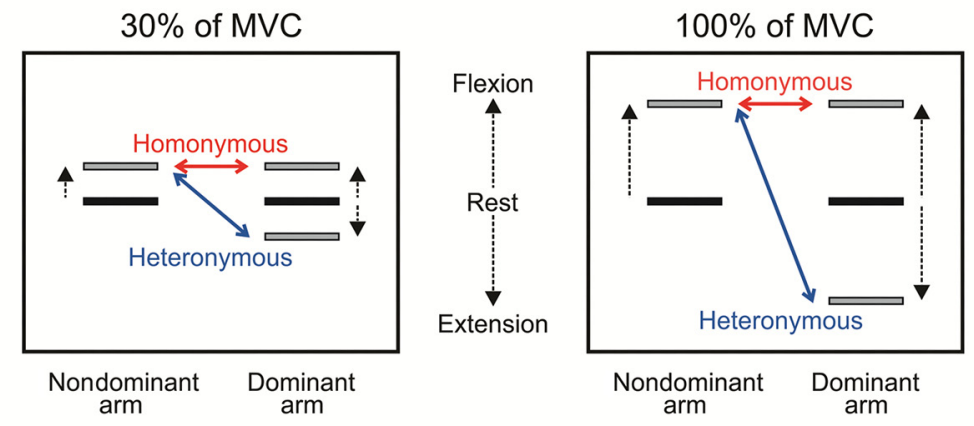

Unilateral
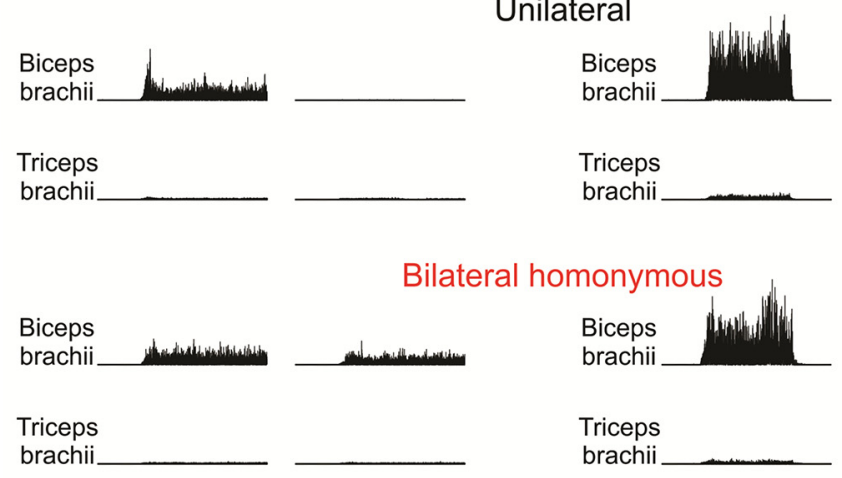

Bilateral homonymous
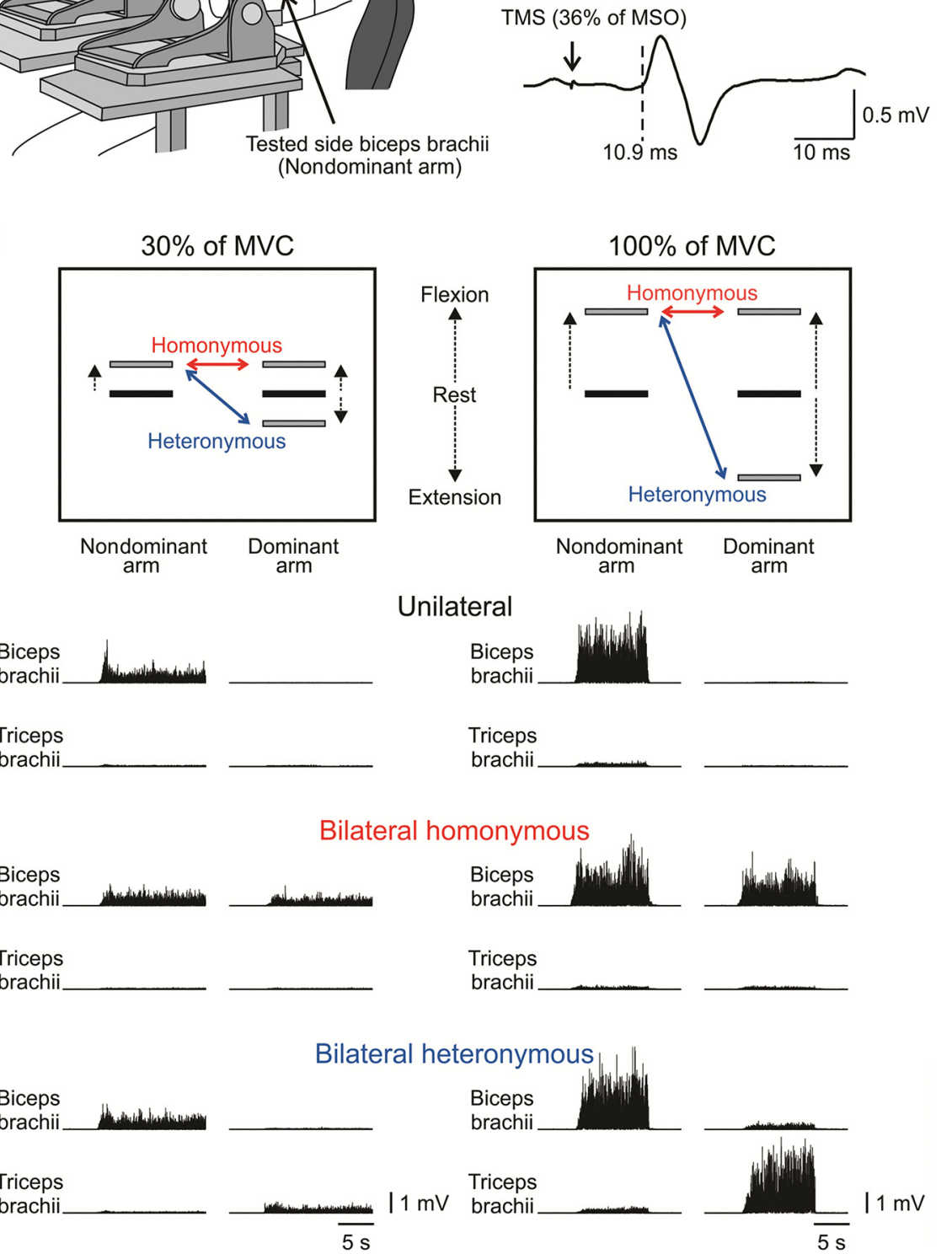

Figure 1. Experimental setup. $A$, Schematics of the experimental setup showing the posture of the elbow and shoulder during testing. $\boldsymbol{B}$, Raw traces showing the average of 20 iMEPs and CMEPs in the biceps brachii muscle during unilateral $30 \%$ of MVC. Arrows indicate the time at which TMS was applied and dotted lines indicate the onset latency of the responses. C, Diagram showing the visual display presented to subjects during testing. Subjects were instructed to perform 30 or $100 \%$ of MVC with the nondominant arm while the dominant arm remained at rest or to perform elbow flexion (bilateral activation of homonymous elbow flexor muscles, red arrow) or extension (bilateral activation of heteronymous elbow flexor and extensor muscles, blue arrow) with same strength as the nondominant arm. Raw EMG traces in biceps and triceps brachii muscles are shown on the lower part of the figure.

cles (Tazoe et al., 2013; Perez et al., 2014). Thus, we hypothesized that bilateral activation of homonymous elbow flexor muscles will result in decrease activity in ipsilateral motor pathways compared with bilateral activation of heteronymous antagonistic muscles. Since neck afferents project bilaterally onto corticore- ticulopropriospinal pathways (Wilson and Peterson, 1981; Sugiuchi et al., 2004), we expected that bilateral effects on ipsilateral motor pathways will be modulated by these afferents.

We examined iMEPs in the biceps brachii muscle during increasing levels of unilateral and bilateral isometric force. We demonstrate that iMEP area and amplitude can be upregulated by bilateral activation of heteronymous arm muscles and downregulated by bilateral activation of homonymous arm muscles. Our results point to the influence of circuits involved in the asymmetric tonic neck reflexes in these bilateral effects acting, at least in part, at the cortical level. We propose that the pattern of bilateral actions may contribute to engage ipsilateral motor pathways in a motor behavior.

\section{Materials and Methods}

Subjects. Seventeen healthy volunteers $(28.3 \pm$ 7.5 years, seven females, two left-handed) participated in the study. All subjects gave informed consent to the experimental procedures, which were approved by the local ethics committee at the University of Pittsburgh. The study was performed in accordance with the Declaration of Helsinki. Subjects were preselected out of a total of 23 individuals who were screened to ensure that they showed iMEPs in the biceps brachii. At the beginning of testing, the best area to elicit iMEPs and cMEPs in biceps brachii was determined in each subject. All subjects included in the study showed a visible iMEP in the biceps brachii during a unilateral elbow flexion of $\geq 30 \%$ of maximal voluntary contraction (MVC) using maximal stimulus intensity (Ziemann et al., 1999).

Experimental sessions. Subjects were seated with both shoulders and elbows flexed by $90^{\circ}$. Custom-built arm devices were used to maintain the position of the left and right arm with load cells attached to measure elbow forces (Fig. 1A). At the beginning of the experiment, all subjects performed 2-3 unilateral isometric MVCs for 3-5 s into elbow flexion and extension, separated by $30 \mathrm{~s}$ of rest. During maximal contractions, subjects were verbally encouraged to perform maximally and visual feedback was provided (Gandevia, 2001). The maximal forces were used to set targets for subsequent submaximal contractions. Subjects participated in two randomized tests in one session where we assessed the latency, area, and amplitude of iMEPs and cMEPs (Fig. $1 B$ ) in the biceps brachii. In one test, subjects performed $30 \%$ of MVC into elbow flexion with the nondominant arm while the contralateral arm remained at rest or performed $30 \%$ of MVC into elbow flexion (bilateral activation of homonymous elbow flexor muscles) or extension (bilateral activation of heteronymous elbow flexor and extensor muscles). In the other test, subjects performed the same tasks exerting 100\% of MVC (Fig. 1C). Left and right forces were displayed as horizontal lines on the left and right side of the screen, respectively. Thus, when both force lines moved upward, subjects 
performed bilateral activation of homologous elbow flexor muscles. When one force line moved upward and the other downward, subjects performed bilateral activation of heteronymous elbow flexor and extensor muscles. In a separate session, the same testing at 30\% of MVC was conducted under different head positions (see iEMPs).

Electromyographic and force recordings. Electromyographic (EMG) activity was recorded bilaterally from the biceps brachii and triceps brachii muscles through surface electrodes (Ag- $\mathrm{AgCl}, 10 \mathrm{~mm}$ diameter) secured to the skin over the belly of each muscle. EMG signals were amplified and filtered (bandwidth, 30-1000 Hz) with a bioamplifier (NeuroLog System, Digitimer). Forces exerted at the elbow were measured bilaterally by two load cells (Honeywell; range, $\pm 111.2 \mathrm{~N}$; voltage, $\pm 5 \mathrm{~V}$; highsensitivity transducer, $0.045 \mathrm{~V} / \mathrm{N}$ ). Force was sampled at $200 \mathrm{~Hz}$ and stored on a computer for off-line analysis. All signals were transformed to digital data with a sampling rate of $5 \mathrm{kHz}$ with a CED 1401 analog-todigital converter (Cambridge Electronic Design) and stored on a computer for off-line analysis.

TMS. TMS was delivered from a Magstim 200 stimulator (Magstim) with a monophasic current waveform. The hot spot for eliciting cMEPs in the dominant biceps brachii was defined as the optimal position in which TMS evoked the largest MEP in the dominant biceps at rest and was determined for each subject using suprathreshold intensity [50$100 \%$ of maximum stimulator output (MSO)]. A figure-eight coil (loop diameter, $7 \mathrm{~cm}$; type number, 16342) was oriented with the handle pointing posterolaterally at $\sim 45^{\circ}$ to the midline. With this coil position, the induced current in the brain flowed in an anteromedial direction and probably produced $\mathrm{D}$ and early I wave activation of corticospinal neurons (Sakai et al., 1997). The TMS coil was held to the head of the subject with a custom coil holder while the head was firmly secured to a headrest by straps to limit head movements. During experiments involving changes in head position, the TMS coil was held to the head of the subject by one of the experimenters. TMS measurements included resting motor threshold (RMT), active motor threshold (AMT), cMEPs, iMEPs, and suppression of voluntary EMG by subthreshold TMS (svEMG). RMT was defined as the minimal stimulus intensity required to induce MEPs of $>50 \mu \mathrm{V}$ peak-to-peak amplitude in 5 of 10 consecutive trials in the relaxed biceps brachii muscle. AMT was defined as the minimal stimulus intensity able to evoke MEPs of $>100 \mu \mathrm{V}$ peak-to-peak amplitude in 5 of 10 consecutive trials during $30 \%$ of MVC with the biceps brachii muscle (Rothwell et al., 1999).

iMEPs. Subjects were asked to perform 30\% of MVC into elbow flexion while maintaining the head straight to examine the hot spot for iMEPs in biceps brachii. Starting at the hot spot for the cMEPs in biceps brachii and with the same coil orientation as that for cMEPs at an intensity of $100 \%$ of MSO, the coil was moved in small steps of $1.0 \mathrm{~cm}$ in all directions until iMEPs were no longer elicited in any direction. During iMEP and cMEP mapping, between 18 and 26 points were tested in each subject. Five pulses were tested at each position and the region with the largest response was measured in centimeters from the $\mathrm{Cz}$ international $10-20$ system. iMEPs and cMEPs with $\geq 100 \mu \mathrm{V}$ peak-to-peak amplitude above background EMG were considered for analysis and the center of gravity (CoG) for each map was calculated (Wassermann et al., 1994). iMEPs were detected using a previously described method (Ziemann et al., 1999). The onset of the iMEP was determined by visual inspection and by using a horizontal cursor showing the mean rectified EMG before the TMS artifact as a reference. iMEP onset was defined as the time point when the EMG exceeded 2 SD above the mean and offset as the time point when the EMG returned through this level. The iMEP area was calculated by the following formula: [area of rectified EMG in iMEP duration/ (mean prestimulus EMG $\times$ iMEP duration) $] \times 100$. The prestimulus EMG area was measured $100 \mathrm{~ms}$ before the TMS artifact. The iMEP peak-to-peak amplitude was measured during the same period as the area was calculated. The same criterion was used to quantify cMEPs. The preferred current direction for eliciting iMEPs was tested at the hot spot for the $\mathrm{CMEP}$ in biceps brachii using the same conditions but rotating the coil $360^{\circ}$ in small steps of $45^{\circ}$ and five pulses were tested at each coil position. Our preliminary testing showed no differences in the size of iMEPs across different coil orientations $\left(F_{(7,35)}=1.03, p=0.43\right)$. Therefore, we performed all other experiments using the anteromedial current direction for testing iMEPs. In experiments involving unilateral and bilateral contractions, 4-5 iMEPs were tested, separated by $30 \mathrm{~s}$ of rest during $30 \%$ of MVC, and 1-2 iMEPs were tested, separated by 1 min of rest during $100 \%$ of MVC. A total of 20 iMEPs were tested in each condition. EMG activity from the nondominant biceps brachii was continuously displayed on an oscilloscope and verbal feedback was provided to the subjects to ensure that physiological measurements were acquired at similar EMG activity at all times. Excluded from further analysis were $9.3 \%$ trials in which mean rectified EMG activity exceeded \pm 2 SD of the average contracting mean rectified EMG, measured $100 \mathrm{~ms}$ before the stimulus artifact (Tazoe and Perez, 2013).

To examine the neuronal inputs involved in changes in iMEP size, we tested the contribution from neck afferents projecting onto iMEPs and cMEPs. Head rotation in the transverse (lateral and medial) and sagittal (flexion and extension) plane produces sensory inputs from neck afferents, which project into vestibulospinal, reticulospinal, and propriospinal neurons (Wilson and Peterson, 1981). In a separate session, subjects performed unilateral $30 \%$ of MVC into elbow flexion with the nondominant arm while the head was maintained straight (as tested previously) or it was rotated maximally laterally (toward) or medially (away) from the biceps brachii muscle tested, and flexed or extended maximally. For comparisons we will refer to head "straight," "lateral," "medial," "flexion," and "extension." These different head positions were also tested during bilateral contraction of homonymous and heteronymous muscles. For comparisons between iMEPs and cMEPs, the intensity for eliciting cMEPs (38.9 $\pm 5.8 \%$ of MSO) was adjusted to match iMEP size at $100 \%$ of MSO.

svEMG. TMS applied at intensities below MEP threshold during voluntary contraction suppresses EMG activity (svEMG; Davey et al., 1994). It is thought that svEMG reflects activation of inhibitory mechanisms within the primary motor cortex (Butler et al., 2007). svEMG was measured in the nondominant motor cortex from where iMEPs were elicited. In one test, svEMG was measured while the subjects performed unilateral elbow flexion at $30 \%$ of MVC with the dominant arm and later during bilateral activation of homonymous muscles with the head straight and with medial head rotation $(n=8)$. In a second test, svEMG was measured while subjects performed unilateral elbow extension at $30 \%$ of MVC with the dominant arm and later during bilateral activation of heteronymous muscles with the head straight and with lateral head rotation $(n=10)$. TMS stimulus intensity was increased in small steps until the svEMG was present without evoking short-latency facilitation during unilateral elbow flexion and extension. If facilitation was observed during unilateral or bilateral contractions, the intensity was reduced and the test repeated in all tasks. The onset of the svEMG was determined by visual inspection and by using a horizontal cursor showing the mean rectified EMG before the TMS artifact as a reference. svEMG onset was defined as the time point when the mean rectified EMG activity dropped below the mean (minimal duration of $10 \mathrm{~ms}$ ) and the end of the svEMG as the time point when the EMG returned through this level. The area of the svEMG was measured between the onset and offset of the svEMG using the following formula: [(background mean rectified EMG $\times$ svEMG duration) au_svEMG], where background mean rectified EMG is the mean amplitude rectified EMG for $100 \mathrm{~ms}$ prestimulus period, and au_svEMG is the area under the rectified svEMG. The svEMG area was normalized against the prestimulus EMG level [svEMG area normalized to prestimulus $\mathrm{EMG}=\mathrm{svEMG}$ area/(background mean rectified EMG $\times$ mean duration of svEMG)]. Mean duration of svEMG was measured in all conditions (biceps brachii, $14.2 \pm 3.6 \mathrm{~ms}$; triceps brachii, $13.9 \pm 4.2 \mathrm{~ms}, p=$ 0.87). The interstimulus interval for TMS pulses was $1 \mathrm{~s}$. Seventy-five trials were tested in each condition.

Data analysis. Normal distribution was tested using the ShapiroWilk's test. Homogeneity of variances was determined using the Levene Median test of equality and Mauchly's test of sphericity. When sphericity could not be assumed, the Greenhouse-Geisser correction statistic was used. Two-factor repeated-measures ANOVAs were performed to determine the effect of head position in the TRANSVERSE (straight, lateral, and medial) or SAGITTAL (straight, flexion, and extension) plane and MEP type (iMEPs and cMEPs) on MEP area, amplitude, and background EMG activity. Two-factor repeated-measures ANOVAs were also per- 
formed to determine the effect of TASK (unilateral, bilateral homonymous, bilateral heteronymous) and FORCE (30 and 100\% of MVC) on iMEP area, amplitude, latency, and duration. Two-factor repeatedmeasures ANOVAs were used to determine the effect of HEAD position (straight, lateral, medial, flexion, and extension) and TASK on iMEP area and amplitude. Additional, repeated-measures ANOVAs were performed to determine the effect of MEDIAL (unilateral straight, unilateral medial, bilateral straight homonymous, and bilateral medial homonymous) or LATERAL (unilateral straight, unilateral lateral, bilateral straight heteronymous, and bilateral lateral heteronymous) head position on iMEP area and amplitude, background EMG activity, and svEMG in conditions needed. Post hoc Holm-Sidak test was used to test for significant comparisons. Pearson correlation analysis was used as needed. Significance was set at $p<0.05$. Group data are presented as the mean $\pm \mathrm{SD}$ in the text.

\section{Results}

\section{iMEP and cMEP localization}

Figure $2 A$ shows the coordinates for the CoG for eliciting iMEPs and cMEPs in all subjects tested. iMEPs were elicited $0.87 \pm 0.5$ $\mathrm{cm}$ anterior and $3.92 \pm 0.4 \mathrm{~cm}$ lateral from $\mathrm{Cz}$ (Fig. $2 B$ ), whereas cMEPs were elicited $0.42 \pm 0.7 \mathrm{~cm}$ anterior and $4.2 \pm 0.2 \mathrm{~cm}$ lateral from $\mathrm{Cz}$ (Fig. 2C). Thus, iMEPs were shifted anteriorly (mean, $0.45 \pm 0.4 \mathrm{~cm}$; range, $0.4-1 \mathrm{~cm}$ in 10 of 16 subjects; $p=$ 0.002 ) and medially (mean, $0.28 \pm 0.5 \mathrm{~cm}$; range, $-0.7-1 \mathrm{~cm}$ in 9 of 16 subjects; $p<0.02$ ) from the CoG of cMEPs. The latencies of iMEPs (mean, $19.5 \pm 1.9 \mathrm{~ms}$; range, 16.8-22.4 ms) were longer compared with cMEPs (mean, $12.7 \pm 1.3 \mathrm{~ms}$; range, 10.9-13.7 ms; $p<0.001$ ). iMEPs (30\% of MVC, $19.5 \pm 1.9 \mathrm{~ms} ; 100 \%$ of MVC, $18.6 \pm 1.3 \mathrm{~ms} ; p=0.16)$ and cMEPs $(30 \%$ of MVC, $12.7 \pm$ $1.3 \mathrm{~ms} ; 100 \%$ of MVC, $12.1 \pm 1.1 \mathrm{~ms} ; p=0.27)$ latencies did not differ across force levels. Although we found no differences in the size of iMEPs across different coil orientations, the most common current directions for eliciting iMEPs were $180^{\circ}$ (anteroposterior in five of seven subjects) or $225^{\circ}$ (mediolateral in four of seven subjects), which differed from the $45^{\circ}$ or $90^{\circ}$ (anteromedial and posteroanterior direction in 16 of 16) for cMEPs.

\section{iMEPs and cMEPs during unilateral voluntary contractions}

Figure 3 illustrates iMEPs and cMEPs in the biceps brachii muscle in a representative subject tested during unilateral 30\% of MVC and different head positions. Note that iMEP size increased during lateral head rotation and during head extension and decreased during medial head rotation and head flexion compared with the head in a straight position. During the same tasks, cMEP size remained unchanged or changed in the opposite direction.

Repeated-measures ANOVA showed a significant interaction between head position in the TRANSVERSE plane and MEP type $\left(F_{(2,28)}=22.64, p<0.001\right.$; Fig. $\left.3 A\right)$ on MEP area. Post hoc analysis demonstrated that iMEP area increased $(p=0.002)$ and decreased $(p=0.002)$ when the head was rotated laterally and medially from the biceps brachii muscle tested compared with iMEPs tested with the head in a straight position (Fig. 3A). Similarly, we found a significant interaction between head position in the TRANSVERSE plane and MEP type $\left(F_{(2,28)}=16.95, p<\right.$ $0.001)$ on MEP amplitude. iMEP amplitude increased $(p=0.04)$ and decreased $(p=0.04)$ when the head was rotated laterally and medially from the biceps brachii muscle tested compared with the head straight. cMEPs in the dominant arm remained unchanged during lateral head rotation (area, $p=0.99$; amplitude, $p=0.85$ ) and increased during medial head rotation (area, $p=$ 0.003; amplitude, $p=0.02$; Fig. $3 B$ ). Mean background rectified EMG activity in the biceps brachii remained similar across conditions $\left(F_{(1.16,16.22)}=1.27, \varepsilon=0.23, p=0.28\right)$.
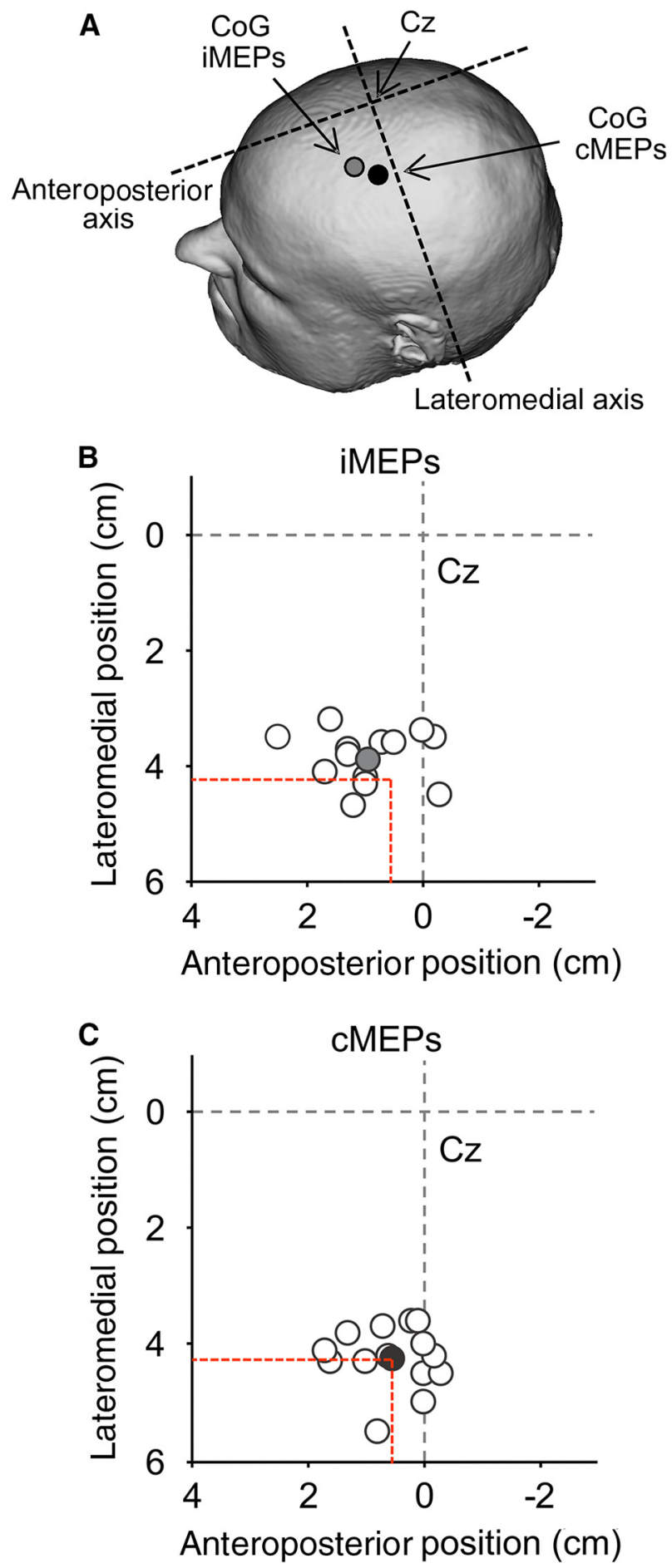

Figure 2. IMEP and CMEP localization. $\boldsymbol{A}$, Schematic illustration of the CoG for iMEPs (gray circle) and cMEPs (black circle). Dotted lines indicate anteroposterior and lateromedial axes according to $\boldsymbol{C z}$. $\boldsymbol{B}, \boldsymbol{C}$, Scatter plots of the CoG for iMEPs $(\boldsymbol{B})$ and $\operatorname{cMEPs}(\boldsymbol{C})$ in individual subjects. The abscissa shows the position in the anteroposterior direction in centimeters ( $\mathrm{cm}$; a negative number indicates posterior). The ordinate shows the position in the lateromedial direction in centimeters. The group average is shown by the gray and black circles. Dotted red lines indicate the center of the $\mathrm{Co}$ for the cMEPs. Note that in most subjects iMEPs were shifted anteriorly and medially from the $\mathrm{C} O \mathrm{G}$ of $\mathrm{cMEPS}$.

We also found a significant interaction between head position in the SAGITTAL plane and MEP type $\left(F_{(2,20)}=4.51, p=0.02\right)$ on MEP area. Post hoc analysis showed that iMEP area increased $(p=0.03)$ and decreased $(p=0.04)$ when the head was extended and flexed compared with the head straight (Fig. 3C). Similar 
results were obtained for iMEP amplitude $\left(F_{(2,20)}=4.02, p=0.03\right)$. cMEP area and amplitude in the dominant arm remained unchanged during head flexion (area, $p=$ 0.77; amplitude, $p=0.85$ ) and extension (area, $p=0.99$; amplitude, $p=0.98$; Fig. 3D). Mean background rectified EMG activity in the biceps brachii remained similar across conditions $\left(F_{(1.04,10.37)}=1.40\right.$, $\varepsilon=0.21, p=0.26)$.

iMEPs during increasing levels of force Figure 4 illustrates iMEPs from a representative participant tested during unilateral and bilateral contractions at increasing levels of force. Note that the amplitude of iMEPs in biceps brachii decreased during bilateral contraction of elbow flexors (homonymous) and increased during bilateral activation of elbow flexor and extensor (heteronymous) muscles compared with unilateral elbow flexion. Note that during testing the head was maintained in the straight position.

Repeated-measures ANOVA showed a significant effect of TASK $\left(F_{(1.41,32.42)}=\right.$ 56.78, $\varepsilon=0.71, p<0.001)$, but not $\operatorname{FORCE}\left(F_{(1,23)}=0.01, p=0.90\right)$ or TASK-FORCE interaction $\left(F_{(2,46)}=2.42\right.$, $p=0.10)$ on iMEP area. Post hoc analysis showed that iMEP area decreased during bilateral contraction of homonymous (30\% of MVC, $88.3 \pm 8.1 \%, p=0.01$; $100 \%$ of MVC, $83.7 \pm 14.2 \%, p=0.04$ ) and increased during bilateral contraction of heteronymous $(30 \%$ of MVC, $116.5 \pm$ $15.1 \%, p=0.001 ; 100 \%$ of MVC, $127.2 \pm$ $22.5 \%, p=0.001)$ muscles compared with a unilateral contraction, regardless of the level of force tested. Similar results were observed for iMEP amplitude (TASK: $F_{(2,46)}=52.87, p<0.001$; FORCE: $F_{(1,23)}$ $=0.004, p=0.99$; TASK-FORCE interaction: $\left.F_{(2,46)}=2.52, p=0.09\right)$. When considering individual subjects, 13 of 15 showed an increase in iMEP area and amplitude during bilateral activation of homonymous muscles, whereas 14 of 15 subjects showed a decrease during bilateral activation of heteronymous muscles. iMEP latency and duration were not different across tasks (latency: $F_{(1.61,36.96)}=0.17, \varepsilon=0.80$, $p=0.80$; duration: $\left.F_{(2,46)}=0.33, p=0.97\right)$ and force levels (latency: $F_{(1,23)}=2.65, p=$ 0.12 ; duration: $\left.F_{(1,23)}=1.54, p=0.23\right)$ tested (Table 1). Mean background rectified EMG activity in biceps brachii was similar across tasks at 30\% $\left(F_{(2,28)}=2.33, p=0.12\right)$ and $100 \%$ $\left(F_{(2,18)}=1.99, p=0.17\right)$ of MVC.

\section{iMEPs during unilateral vs. bilateral voluntary contractions} Figure 5 illustrates iMEPs from a representative participant. Note that iMEP amplitude in biceps brachii decreased during bilateral
Head position - Transverse plane
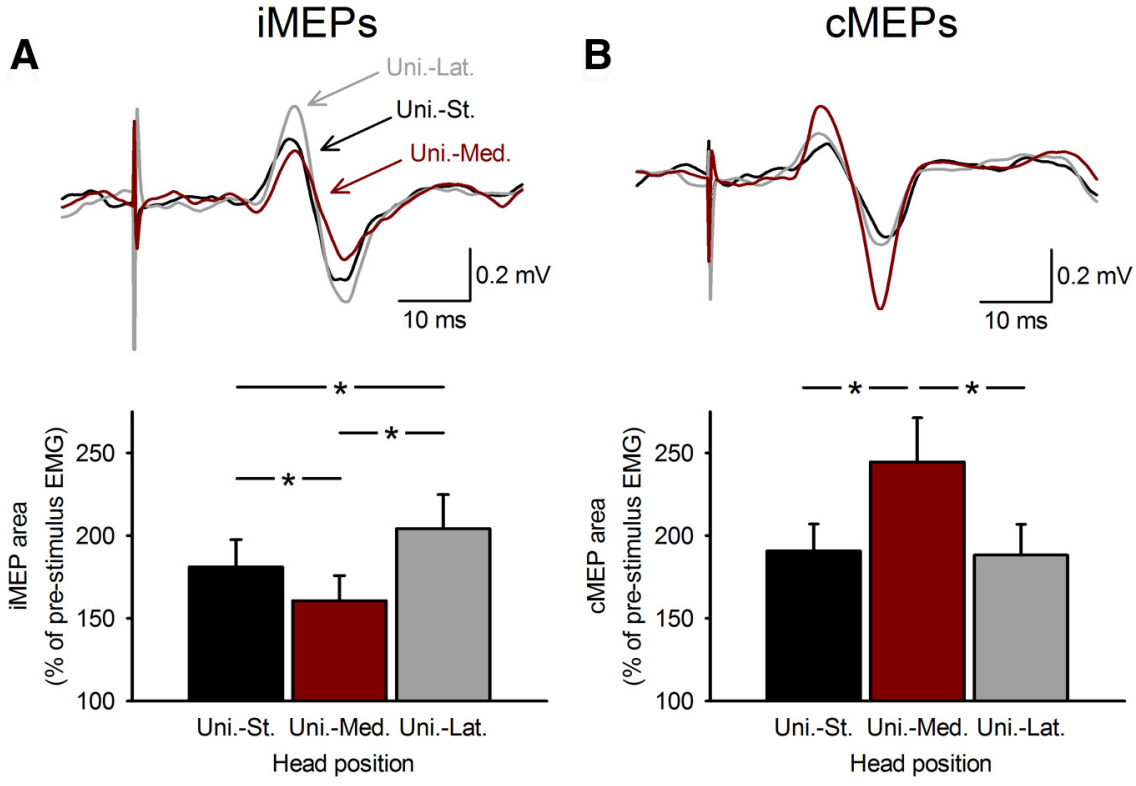

Head position - Sagittal plane
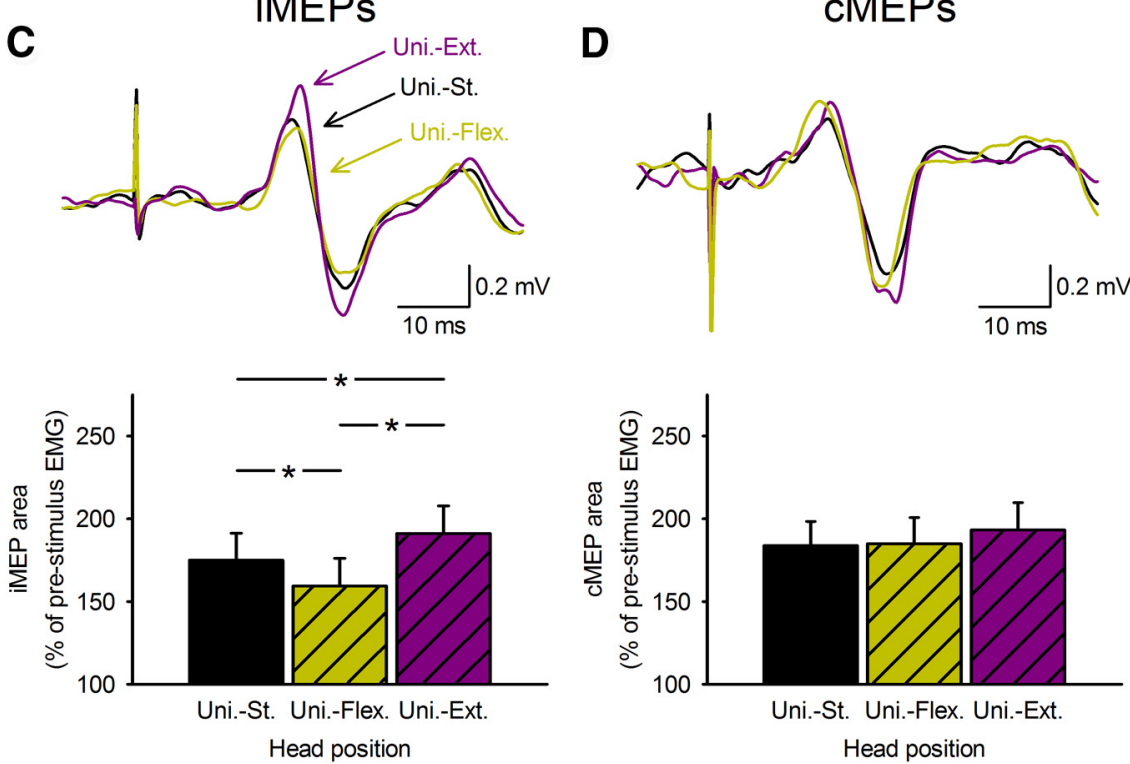

Figure 3. iMEPs and CMEPs during unilateral voluntary contractions. Raw EMG traces recorded from the biceps brachii muscle in a representative subject during unilateral $30 \%$ of MVC into elbow flexion. Traces show the average data in 20 trials. $A-D$, iMEPs and cMEPs in biceps brachii muscle were tested while maintaining the head in a straight position and during head rotations in the transverse $(\boldsymbol{A}, \boldsymbol{B}$, $n=11)$ and sagittal $(\boldsymbol{C}, \boldsymbol{D}, n=15)$ plane. In all graphs, the abscissa shows the conditions tested [unilateral contraction with the head straight (Uni.-St.), blackbars; unilateral contraction with medial head rotation (Uni.-Med.), dark red bars; unilateral contraction with lateral head rotation (Uni.-Lat.), gray bars; unilateral contraction with head flexion (Uni.-Flex.), hatched dark yellow bars; unilateral contraction with head extension (Uni.-Ext.), hatched purple bars]. The ordinate shows theiMEP area. Note that iMEP area decreased during medial head rotation and head flexion, whereas iMEP area increased during lateral head rotation and head extension. During the same tasks, cMEPs remained unchanged or changed in the opposite direction. Error bars indicate SEM. ${ }^{*} p<0.05$.

activation of homonymous muscles to a larger extent when the head was medially rotated and increased to a larger extent during bilateral activation of heteronymous muscles when the head was laterally rotated compared with other conditions tested.

Repeated-measures ANOVA showed a significant effect of MEDIAL head position on iMEP area $\left(F_{(3,27)}=15.79, p<0.001\right)$ 


\section{$30 \%$ of MVC}

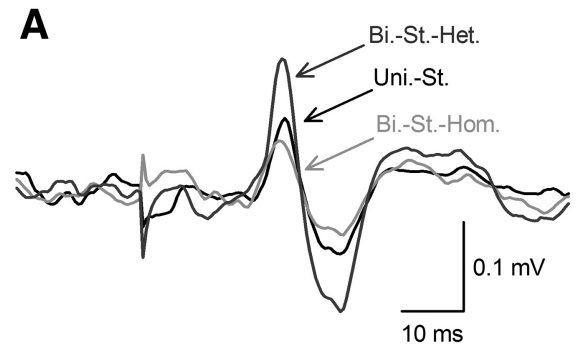

B

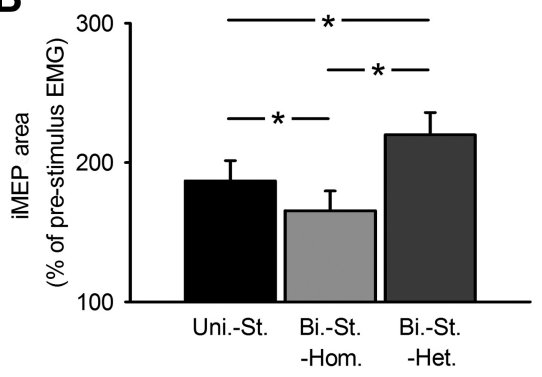

$100 \%$ of MVC
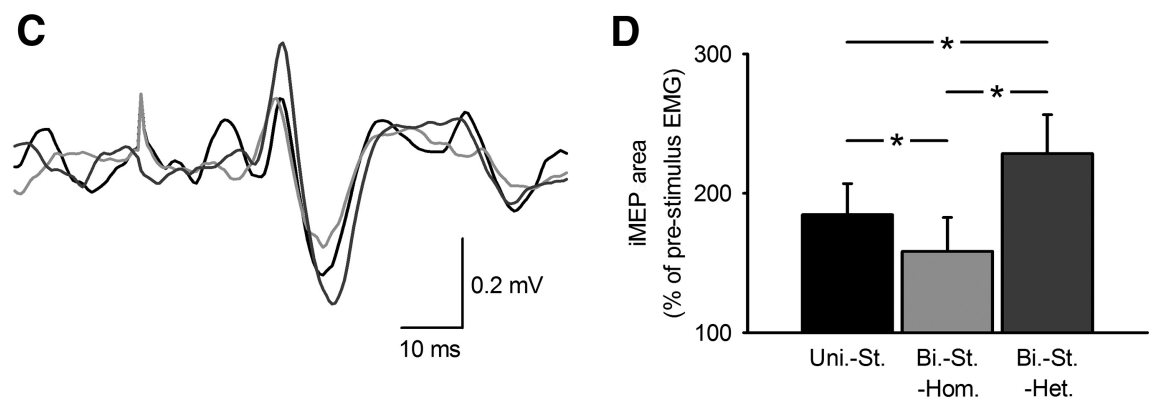

Figure 4. iMEPs during increasing levels of force. $A, C$, Raw EMG traces recorded from the biceps brachii muscle in a representative subject during unilateral and bilateral contractions at $30(\boldsymbol{A})$ and $100 \%(\boldsymbol{C})$ of MVC with the head maintained in a straight position. Traces show the average EMG data in 20 trials. Note that the subject showed smaller iMEPs during bilateral activation of homologous muscles (light gray traces) and larger iMEPs during bilateral activation of heteronymous muscles (dark gray traces) compared with unilateral contraction, regardless of the force level tested. B, D, Group data ( $30 \%$ of MVC, $n=15 ; 100 \%$ of MVC, $n=10$ ). The abscissa shows the conditions tested (Uni.-St., unilateral contraction with the head straight; Bi.-St.-Hom., bilateral contraction of homologous muscles with the head straight; Bi.-St.-Het., bilateral contraction of heteronymous muscles with the head straight). The ordinate shows the iMEP area; ${ }^{*} p<0.05$.

and amplitude $\left(F_{(3,27)}=37.98, p<0.001\right)$. Post hoc analysis showed that iMEP area and amplitude decreased to the same extent during unilateral contraction with medial head rotation and during bilateral activation of homonymous muscles with the head straight (area, $p=0.99$; amplitude, $p=0.98$ ) compared with a unilateral contraction with the head straight, whereas the combination of bilateral activation of homonymous muscles and medial head rotation decreased iMEP area and amplitude (area, $79.3 \pm 7.4 \%, p<0.05$; amplitude, $70.9 \pm 9.0 \%, p<0.001)$ to a larger extent (Fig. $5 B$ ). Mean background rectified EMG activity in biceps brachii was similar across conditions $\left(F_{(3,27)}=0.21, p=\right.$ $0.89)$.

LATERAL head position also had a significant effect on iMEP area $\left(F_{(3,27)}=20.24, p<0.001\right)$ and amplitude $\left(F_{(3,27)}=16.65\right.$, $p<0.001)$. Post hoc analysis showed that iMEP area and amplitude increased similarly during unilateral contraction with lateral head rotation and bilateral activation of heteronymous muscles with head straight (area, $p=0.93$; amplitude, $p=0.99$ ) compared with unilateral contraction with head straight. However, bilateral activation of heteronymous muscles combined with lateral head rotation increased iMEP area and amplitude to a larger extent than all other conditions (area, $131.0 \pm 13.4 \%, p<0.01$; amplitude, $144.1 \pm 16.1 \%, p<0.001$; Fig. 5D). Mean background rectified EMG activity in biceps brachii remained similar across conditions $\left(F_{(3,27)}=0.08, p=0.97\right)$.

We also compared the effect of all head positions on iMEP size during bilateral contractions (Fig. 6A). We found a significant effect of TASK $\left(F_{(1,10)}=27.15, p<0.001\right)$, HEAD position
$\left(F_{(4,40)}=27.46, p<0.001\right)$, and TASKHEAD position interaction $\left(F_{(4,40)}=\right.$ $10.59, p<0.001)$ on iMEP area. Post hoc analysis showed that during bilateral contraction of heteronymous muscles, iMEP area increased with lateral head rotation $(132.8 \pm 14.2 \%, p<0.001)$ and remained unchanged during medial head rotation (97.8 $\pm 10.5 \%, p=0.99)$ compared with during unilateral contraction with the head straight. Similarly, during bilateral contraction of homonymous muscles, iMEP area decreased with medial head rotation $(79.2 \pm 7.2 \%, p<0.001)$ and remained unchanged during lateral head rotation $(106.7 \pm 8.1 \%, p=0.26)$ compared with during unilateral contraction with the head straight. Similar results were obtained for iMEP amplitude (TASK: $F_{(1,10)}=17.40, p=0.002$; HEAD position: $F_{(4,40)}=6.07, p=0.002$; TASKHEAD position interaction: $F_{(4,40)}=2.98$, $p=0.03)$. No effects were observed on iMEP area and amplitude during bilateral contraction of homonymous and heteronymous muscles with head flexion (homonymous: area, $95.1 \pm 7.4 \%, p=0.45$; amplitude; $93.7 \pm 18.4 \%, p=0.92$ ); heteronymous: area, $105.5 \pm 14.4 \%, p=$ 0.94; amplitude, $105.6 \pm 27.3 \%, p=0.89)$ and extension (homonymous: area, $103.4 \pm 9.4 \%, p=0.95$; amplitude, $96.9 \pm 20.7 \%, p=0.99$; heteronymous: area, $105.5 \pm 12.3 \%, p=0.97$; amplitude, $107.2 \pm 27.8 \%, p=0.48)$ when mean background rectified EMG activity was similar across conditions $\left(F_{(8,80)}=0.71, p=0.68\right)$.

A positive correlation was found between changes in iMEP area during bilateral activation of heteronymous muscles with lateral head rotation and bilateral activation of homonymous muscles with medial head rotation $(r=0.73, p=0.01$; Fig. $6 B)$. In contrast, we observed no correlation between changes in iMEP size during bilateral contraction of heteronymous muscles with extension of the head and bilateral contraction of homonymous muscles with flexion of the head ( $r=0.35, p=0.29$; Fig. $6 C)$.

svEMG during unilateral vs. bilateral voluntary contractions To examine a possible contribution of intracortical inhibitory circuits to the modulation of iMEPs, we measured svEMG in the dominant arm. Figure 7 illustrates mean rectified EMG activity in the biceps and triceps brachii muscles during subthreshold TMS in a representative subject. Note that the svEMG area increased to a larger extent during bilateral contraction of homonymous muscles when the head is medially rotated and decreased during bilateral contraction of heteronymous muscles when the head is laterally rotated.

Repeated-measures ANOVA showed a significant effect of MEDIAL head position on the svEMG area $\left(F_{(2,14)}=17.20, p<\right.$ $0.001)$. Post hoc analysis demonstrated that the svEMG area increased during bilateral activation of homonymous muscles $(153.6 \pm 45.7 \%, p=0.004)$ compared with unilateral contraction. In addition, the svEMG area was further increased when bilateral activation of homonymous muscles was combined with 
Table 1. iMEP latency and duration

\begin{tabular}{|c|c|c|c|c|c|c|}
\hline \multirow[b]{2}{*}{ Task } & \multicolumn{3}{|l|}{$30 \%$ of MVC } & \multicolumn{3}{|c|}{$100 \%$ of MVC } \\
\hline & Uni.-St. & Bi.-St.-Hom. & Bi-St.-Het. & Uni.-St. & Bi.-St.-Hom. & Bi-St.-Het. \\
\hline Latency (ms) & $19.5 \pm 1.9$ & $19.5 \pm 1.8$ & $19.6 \pm 1.5$ & $18.6 \pm 1.3$ & $18.9 \pm 0.9$ & $18.5 \pm 2.0$ \\
\hline Duration (ms) & $14.9 \pm 2.9$ & $16.3 \pm 3.7$ & $14.7 \pm 3.2$ & $13.6 \pm 7.9$ & $13.7 \pm 4.1$ & $13.8 \pm 8.0$ \\
\hline
\end{tabular}
with the head straight.

medial head rotation $(187.1 \pm 60.1 \%, p<$ $0.03)$. LATERAL head position also revealed a significant effect on the svEMG area $\left(F_{(2,18)}=28.71, p<0.001\right)$. Post hoc analysis showed that the svEMG area decreased during bilateral activation of heteronymous muscles $(75.7 \pm 21.2 \%, p<$ $0.001)$ compared with unilateral contraction. Furthermore, the decrease in the svEMG area was enhanced when bilateral activation of heteronymous muscle combined with lateral head rotation (54.8 \pm $21.5 \%, p=0.003)$. Mean background rectified EMG activity remained similar across conditions (biceps, $F_{(2,14)}=0.28$, $p=0.76$; triceps, $\left.F_{(2,18)}=0.96, p=0.41\right)$.

\section{Discussion}

Our findings indicate that ipsilateral motor pathways projecting to proximal arm muscles can be selectively modulated by voluntary contraction of contralateral arm muscles, likely involving circuits mediating asymmetric tonic neck reflexes acting, at least in part, at the cortical level. We found that iMEP area and amplitude decreased during bilateral activation of homonymous elbow flexor muscles and increased during bilateral activation of heteronymous elbow flexor and extensor muscles compared with unilateral contractions, regardless of the level of force tested. Medial (away from the muscle tested) and lateral (toward the muscle tested) rotation of the head selectively enhanced effects on iMEPs during bilateral activation of homonymous and heteronymous muscles, respectively. In contrast, head flexion and extension exerted nonspecific bilateral effects on iMEPs. Intracortical inhibition in the primary motor cortex where iMEPs originated showed modulation compatible with the changes in iMEPs. We argue that the pattern of bilateral actions may represent a strategy to selectively engage ipsilateral motor pathways in a motor behavior.

\section{Evidence for activation of ipsilateral motor pathways}

A first question to address in our study is whether we were able to stimulate and dissociate corticofugal fibers mediating ipsilateral and contralateral biceps brachii MEPs. Our results agree with previous findings showing that iMEPs in biceps brachii had higher threshold and longer latencies compared with cMEPs (Wassermann et al., 1991, 1994; Ziemann et al., 1999; Bawa et al., 2004). We also found that iMEPs in biceps brachii were elicited
Head position - Transverse plane - Medial
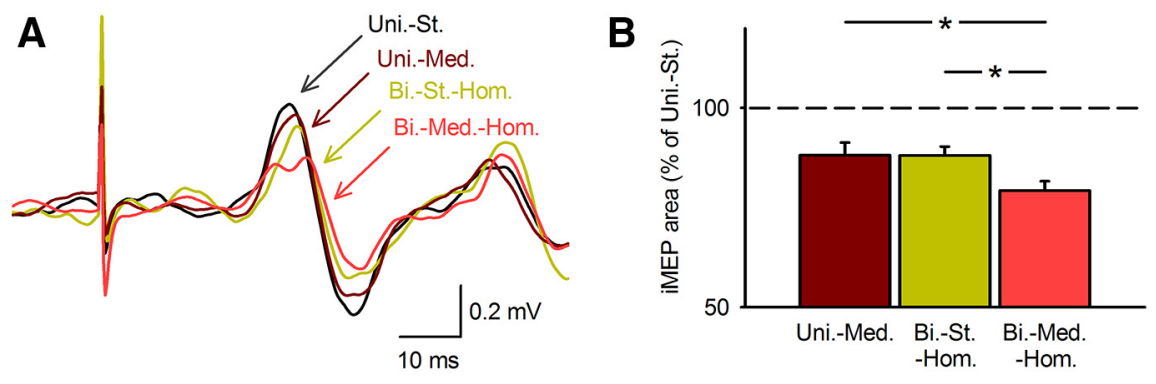

Head position - Transverse plane - Lateral
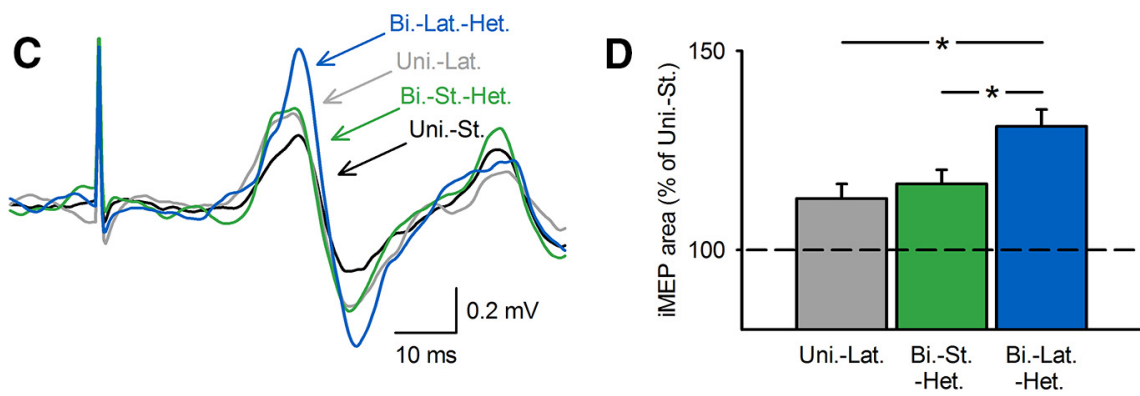

Figure 5. iMEPs during unilateral vs. bilateral voluntary contractions. $A, C$, Raw EMG traces recorded from the biceps brachii muscle in a representative subject during unilateral and bilateral contractions at $30 \%$ of MVC while the head position was changed the transverse plane into the medial $(\boldsymbol{A})$ and lateral ( $\boldsymbol{C}$ ) direction. Traces show the average EMG data in 20 trials. Note that iMEP traction of homonymous muscles with the head straight (dark yellow trace), compared with unilateral contraction with head (bilateral contraction of homonymous muscles was combined with medial head rotation, the iMEP drated laterally (gray trace) and bilateral contraction of heteronymous muscles with the head straight (green trace), (black trace). Here, when bilateral contraction of heteronymous muscles conditions tested ( $\boldsymbol{B}$, Uni.-Med., unilateral contraction with medial head rotation; Bi.-St.-Hom., bilateral contraction of rom straight; Bi.-Med.-Hom., bilateral contraction of homonymous muscles with the head medially with the head straight; Bi.-Lat.-Het., bilateral contraction of heteronymous muscles with the head laterally rotated). The ordinate shows the iMEP area. Error bars indicate SEM. ${ }^{*} p<0.05$.

from an area in motor cortex located more medial and anterior than the area for cMEPs. This agrees with previous studies showing differences across scalp locations for eliciting iMEPs and cMEPs (Wassermann et al., 1994; Ziemann et al., 1999), although other studies found no differences (MacKinnon et al., 2004). The variability between results might be in part related to the muscles tested since the region for evoking iMEPs has been found to differ between proximal muscles even within the same subject (MacKinnon et al., 2004). The anteromedial shift observed in the majority of our subjects may represent a sensitive region for testing these responses in humans. iMEPs likely involve corticoreticulopropriospinal pathways (Ziemann et al., 1999; Bradnam et al., 2013); thus, it is possible that changes in these pathways contrib- 
A
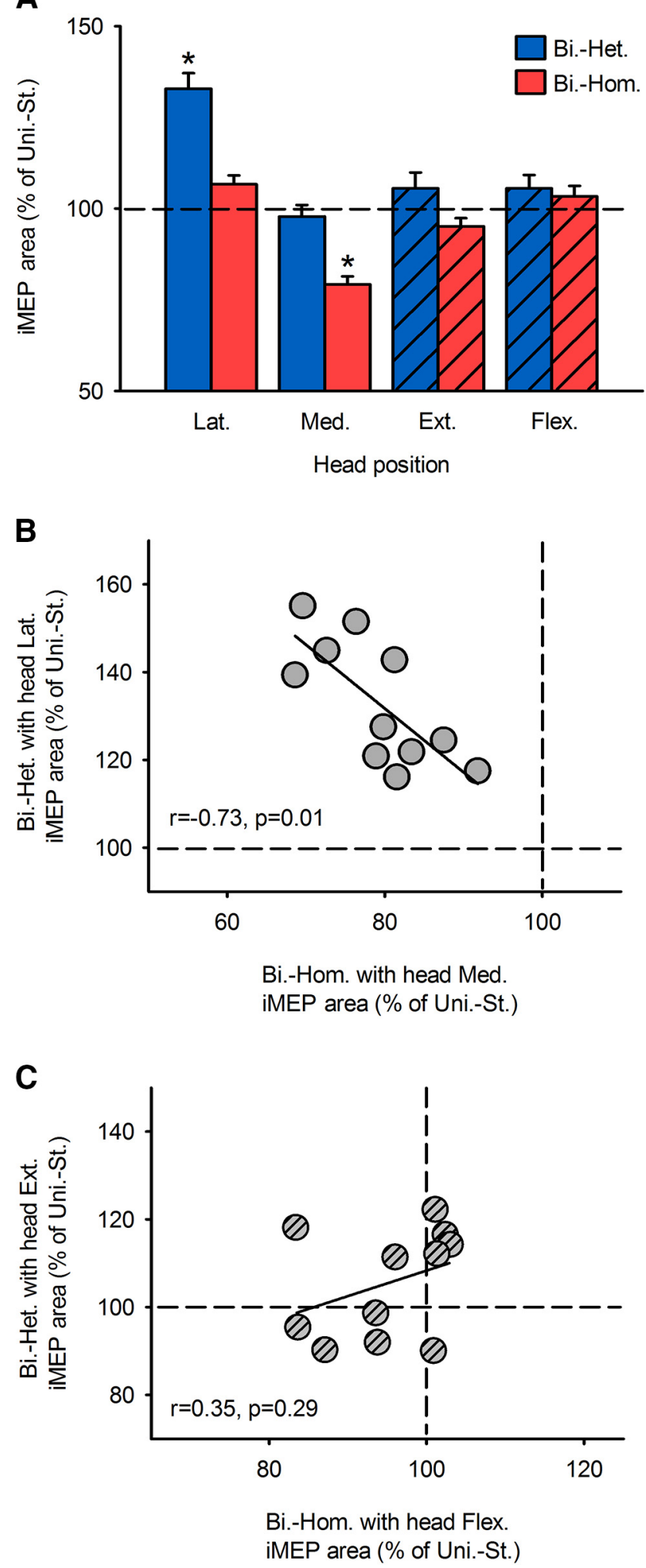

Figure 6. iMEPs and correlations. $\boldsymbol{A}$, Group data $(n=11)$. The abscissa shows the head position tested (Lat., lateral head rotation; Med., medial head rotation; Flex., head flexion; Ext., head extension) during bilateral contraction of homologous (red bars) and heteronymous (blue bars) compared with a unilateral contraction with the head straight (dotted line). The ordinate shows the iMEP area normalized to the iMEP area during unilateral contraction with the head straight. $\boldsymbol{B}$, Graph shows correlation analysis between the changes in iMEP area during bilateral contraction of heteronymous muscles with lateral head rotation and the iMEP area during bilateral contraction of homonymous muscles with medial head rotation. Note here that uted to this result. Reticulospinal projections to ipsilateral proximal arm muscles have been reported from areas more anterior and medial than for contralateral responses (Davidson and $\mathrm{Bu}-$ ford, 2006). The preferred current direction for eliciting iMEPs in most subjects was mediolateral or anteroposterior, which differs from the anteromedial direction for cMEPs (Sakai et al., 1997) supporting the view that different pathways were activated.

Another source to identify iMEPs comes from testing the effect of changes in head position. In agreement with previous results (Ziemann et al., 1999), we found that iMEP size increased during unilateral voluntary contraction with lateral head rotation (toward the muscle tested) and decreased during medial head rotation (away from the muscle tested). We also found that head flexion decreased and head extension increased iMEP size. This result agrees with the extensive projections from afferents from vestibular and neck reflexes onto ipsilateral descending motor pathways (Wilson and Peterson, 1981; Sugiuchi et al., 2004). Indeed, increases in iMEP size during head extension support evidence showing that the excitability of forelimb muscles increased by nose-up rotation (Wilson et al., 1986). The differences between iMEP sizes across head positions agree with the asymmetric and symmetric tonic neck reflexes. In both tests, when the head turned into the direction of the extended limb (i.e., lateral head rotation for asymmetric reflex and extension of the head for the symmetric reflex), we found that iMEP size increased and that the opposite effect occurred in the other direction. This also agrees with the different results found in cMEPs during the same tasks and with evidence showing that tonic neck reflexes are still present in intact adults (Bruijn et al., 2013). Thus, during unilateral isometric voluntary activity, corticofugal fibers mediating iMEPs receive both excitatory and inhibitory inputs from afferents involved in both asymmetric and symmetric tonic neck reflexes.

Neural mechanisms contributing to iMEP modulation during bilateral voluntary contractions

An intriguing question is why bilateral activation of homonymous and heteronymous proximal muscles exerted differential effects on iMEPs. We found that iMEP area and amplitude was downregulated by bilateral activation of homonymous elbow flexor muscles and upregulated by bilateral activation of heteronymous elbow flexor and extensor muscles. These results agree with recent studies showing that interhemispheric inhibitory interactions between motor cortices were stronger during bilateral activation of homonymous muscles and weaker during bilateral activation of heteronymous muscles (Tazoe et al., 2013; Perez et al., 2014). However, it is less likely that this mechanism contributed to our results. The latency for iMEPs is shorter than for interhemispheric inhibitory effects, suggesting that these transcallosal influences occurred at a later time. As background EMG activity was maintained constant across conditions, it is difficult to assess compensatory actions between the contralateral and ipsilateral corticospinal pathway in spinal motoneurons. It is also less likely that changes in motoneuronal excitability contributed to changes in iMEP size because no modulation at this level was

subjects with strong bilateral effects during lateral head rotation also showed strong bilateral effects on iMEPs during medial head rotation. C, Graph shows correlation analysis between the changes in iMEP area during bilateral contraction of heteronymous muscles with head flexion and IMEP area during bilateral contraction of homonymous muscles with head flexion. Note here that head flexion and extension did not have any specific bilateral effects on iMEPs. Error bars indicate SEM. ${ }^{*} p<0.05$. 
A
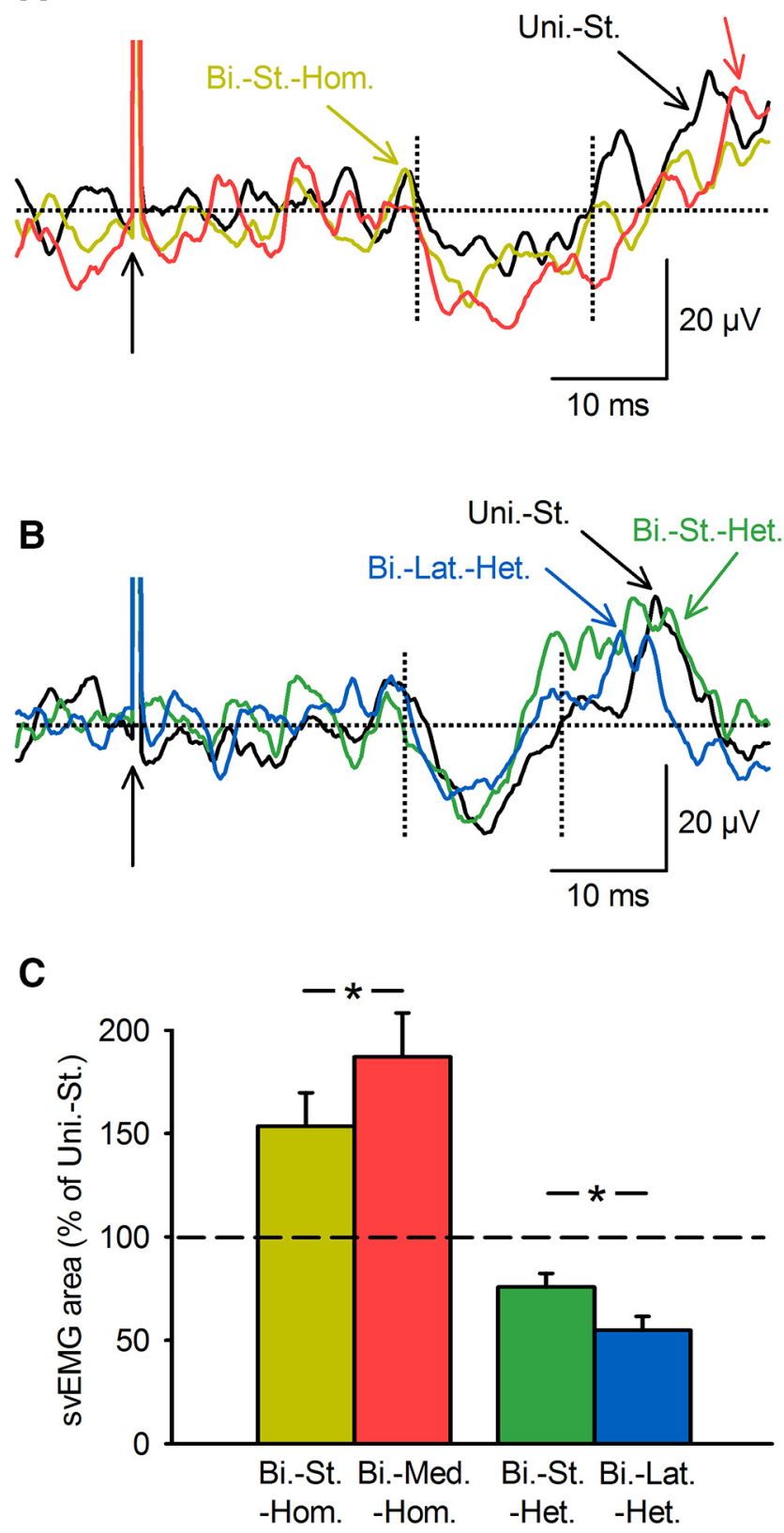

Figure 7. svEMG during unilateral vs. bilateral voluntary contractions. $\boldsymbol{A}, \boldsymbol{B}$, Raw EMG traces recorded from biceps brachii $(\boldsymbol{A})$ and triceps brachii $(\boldsymbol{B})$ muscles in a representative subject during unilateral and bilateral contraction at $30 \%$ of MVC while the head position was changed in the transverse plane. Seventy-five traces were averaged in each set. The time of stimulation is indicated by black arrows. Note that compared with unilateral contraction with head straight (black trace), the svEMG area in biceps brachii increased during bilateral contraction of homonymous muscles with head straight (dark yellow trace) and further increased during bilateral contraction of homonymous muscles with medial head rotation (orange trace). In contrast, the svEMG area in triceps brachii decreased during bilateral contraction of heteronymous muscles with head straight (green trace) and further decreased (blue trace) during bilateral contraction of heteronymous muscles with lateral head rotation compared with unilateral contraction with head straight (black trace). C, Group data (biceps, $n=8$; triceps, $n=10$ ). The abscissa shows the conditions tested (Bi.-St.-Hom., bilateral contraction of homologous muscles with the head straight; Bi.-Med.-Hom., bilateral contraction of homonymous muscles with the head medially rotated; Bi.-St.-Het., bilateral contraction of heteronymous muscles with the head straight; Bi.-Lat.-Het., bilateral contraction of heteronymous muscles with the head laterally rotated) and the ordinate shows the svEMG area normalized to the svEMG area during unilateral contraction with head straight. Error bars indicate SEM. ${ }^{*} p<0.05$. reported during similar motor tasks (Perez et al., 2014). Our results point at the influence of intracortical mechanisms. We found that intracortical inhibition, measured in the primary motor cortex where iMEPs originated, increased and decreased during bilateral activation of homonymous and heteronymous muscles, respectively. The bidirectional modulation of intracortical inhibition was further enhanced by rotation of the head, which is compatible with the modulation of iMEPs. Thus, it is possible that circuits involved in the asymmetric tonic neck reflex contributed to these cortical effects. Neck afferent inputs through the dorsal column nuclei convey to intraparietal areas (Edney and Porter, 1986; Prevosto et al., 2011), which project to the primary motor cortex (Strick and Kim, 1978). Also, combined inputs from neck and vestibular afferents arrive in the vestibular nuclei, which project and receive inputs from the primary motor cortex (Fukushima, 1997). In humans, a block of the C1-C3 cervical roots, which are involved in tonic neck reflexes (McCouch et al., 1950), results in symptoms that mimic vestibular deficits (de Jong et al., 1977), supporting the convergence of neck and vestibular afferents onto common neural elements.

Evidence showed that afferents involved in the asymmetric tonic neck reflex influence voluntary activity (Tokizane et al., 1951; Hellebrandt et al., 1956; Fukuda, 1961) and play a role in postural responses (Wilson, 1988). Thus, the more robust changes in iMEP size during bilateral contractions combined with lateral and medial head rotation might not be surprising. However, we found that afferents involved in the symmetric tonic neck reflex (during head flexion and extension) did not affect iMEP size during bilateral contractions. Because it was shown that effects from neck afferents during flexion and extension movements onto forelimb motoneurons are weak and more variable (Lindsay et al., 1976; Lacquaniti et al., 1984; Wilson et al., 1986), it is possible that signals from these movements were not strong enough during bilateral contractions to change iMEPs. Although, during a unilateral contraction, iMEP size changed with head flexion and extension, a fact that supports the likelihood of an interaction.

\section{Biological and functional significance}

An increasing number of studies propose that ipsilateral motor pathways play a role in the recovery of motor function after injury (Netz et al., 1997; Thuret et al., 2006; Brus-Ramer et al., 2007; Bradnam et al., 2013). In fact, cortical signals from ipsilateral arm movements have been successfully used to control brainmachine-interface paradigms in humans and nonhuman primates (Carmena et al., 2003; Ganguly et al., 2009). A question that remains poorly understood is how ipsilateral motor pathways are engaged in voluntary motor behavior.

Here, we demonstrate that it is possible to selectively modulate the excitability of ipsilateral motor pathways during bilateral contractions by involving head rotations, which likely stimulate neck and vestibular receptors. In cats, inputs from neck and vestibular afferents project onto ipsilateral vestibulospinal, reticulospinal, and propriospinal neurons (Wilson and Peterson, 1981). These ipsilateral descending pathways contribute to integrate feedback to upper-limb muscles during movement (Schepens and Drew, 2006; Alstermark and Isa, 2012) and likely mediate iMEPs in humans (Ziemann et al., 1999; Bradnam et al., 2013). In nonhuman primates, neck and vestibular afferents are involved in compensatory postural reflexes and motor coordination (Cohen, 1961; Angelaki and Cullen, 2008; Cullen, 2012). This integrated information projects to the reticular formation, which is largely involved in asymmetric muscle activation between bilat- 
eral arm flexors and extensors (Davidson et al., 2007). Such reciprocal organization, allowing excitation of ipsilateral elbow flexors and contralateral elbow extensors, corresponds well with our finding of increased iMEP size during bilateral contraction of heteronymous muscles, and it was suggested to support reaching movements with one limb while sustaining the body with another limb (Schepens and Drew, 2006; Davidson et al., 2007).

From a functional perspective, combining lateral head rotation with bilateral activation of heteronymous elbow flexor and extensor muscles might represent a strategy to maximize ipsilateral descending activity to upper-limb motoneurons, whereas in individuals with strong flexion reflex synergies (Dewald et al., 1995), the opposite head rotation and upper-limb muscle activation might be more helpful. Notably, inputs from asymmetric tonic neck reflexes have been used as an adjunct approach to enhance voluntary output in upper-limb muscles in healthy subjects (Berntson and Torello, 1977; Le Pellec and Maton, 1993) and in patients with motor disorders (Ellis et al., 2012). In contrast, afferent inputs from symmetric tonic neck reflexes resulted in a more unstable motor behavior (Brandt et al., 1981; Buckley et al., 2005). The contribution of neck reflexes to posture is task dependent and can be manifested at intermediate and strong levels of muscle activity (Hellebrandt et al., 1956; Fukuda, 1961; Bruijn et al., 2013). Thus, it is unclear whether our effects will be present at lower levels of bilateral muscle contraction agreeing with the need of performing relatively intermediate levels of contraction to elicit iMEPs. Overall, our results highlight that a better understanding of how ipsilateral motor pathways are engaged during a voluntary motor behavior may contribute to understand the involvement of this route in the recovery of function after injury.

\section{References}

Alstermark B, Isa T (2012) Circuits for skilled reaching and grasping. Annu Rev Neurosci 35:559-578. CrossRef Medline

Alstermark B, Lundberg A, Sasaki S (1984) Integration in descending motor pathways controlling the forelimb in the cat. 10. Inhibitory pathways to forelimb motoneurones via C3-C4 propriospinal neurones. Exp Brain Res 56:279-292. CrossRef Medline

Angelaki DE, Cullen KE (2008) Vestibular system: the many facets of a multimodal sense. Annu Rev Neurosci 31:125-150. CrossRef Medline

Armand J, Kuypers HG (1980) Cells of origin of crossed and uncrossed corticospinal fibers in the cat: a quantitative horseradish peroxidase study. Exp Brain Res 40:23-34. Medline

Bawa P, Hamm JD, Dhillon P, Gross PA (2004) Bilateral responses of upper limb muscles to transcranial magnetic stimulation in human subjects. Exp Brain Res 158:385-390. Medline

Berntson GG, Torello MW (1977) Expression of magnus tonic neck reflexes in distal muscles of prehension in normal adults. Physiol Behav 19:585587. CrossRef Medline

Bradnam LV, Stinear CM, Lewis GN, Byblow WD (2010a) Task-dependent modulation of inputs to proximal upper limb following transcranial direct current stimulation of primary motor cortex. J Neurophysiol 103: 2382-2389. CrossRef Medline

Bradnam LV, Stinear CM, Byblow WD (2010b) Theta burst stimulation of human primary motor cortex degrades selective muscle activation in the ipsilateral arm. J Neurophysiol 104:2594-2602. CrossRef Medline

Bradnam LV, Stinear CM, Byblow WD (2013) Ipsilateral motor pathways after stroke: implications for noninvasive brain stimulation. Front Hum Neurosci 7:184. CrossRef Medline

Brandt T, Krafczyk S, Malsbenden I (1981) Postural imbalance with head extension: improvement by training as a model for ataxia therapy. Ann N Y Acad Sci 374:636-649. CrossRef Medline

Brinkman J, Kuypers HG (1973) Cerebral control of contralateral and ipsilateral arm, hand and finger movements in the split-brain rhesus monkey. Brain 96:653-674. CrossRef Medline

Bruijn SM, Massaad F, Maclellan MJ, Van Gestel L, Ivanenko YP, Duysens J
(2013) Are effects of the symmetric and asymmetric tonic neck reflexes still visible in healthy adults? Neurosci Lett 556:89-92. CrossRef Medline

Brus-Ramer M, Carmel JB, Chakrabarty S, Martin JH (2007) Electrical stimulation of spared corticospinal axons augments connections with ipsilateral spinal motor circuits after injury. J Neurosci 27:13793-13801. CrossRef Medline

Buckley JG, Anand V, Scally A, Elliott DB (2005) Does head extension and flexion increase postural instability in elderly subjects when visual information is kept constant? Gait Posture 21:59-64. CrossRef Medline

Butler JE, Larsen TS, Gandevia SC, Petersen NT (2007) The nature of corticospinal paths driving human motoneurones during voluntary contractions. J Physiol 584:651-659. CrossRef Medline

Carmena JM, Lebedev MA, Crist RE, O’Doherty JE, Santucci DM, Dimitrov DF, Patil PG, Henriquez CS, Nicolelis MA (2003) Learning to control a brain-machine interface for reaching and grasping by primates. PLoS Biol 1:E42. Medline

Cohen LA (1961) Role of eye and neck proprioceptive mechanisms in body orientation and motor coordination. J Neurophysiol 24:1-11. Medline

Cullen KE (2012) The vestibular system: multimodal integration and encoding of self-motion for motor control. Trends Neurosci 35:185-196. CrossRef Medline

Davey NJ, Romaiguère P, Maskill DW, Ellaway PH (1994) Suppression of voluntary motor activity revealed using transcranial magnetic stimulation of the motor cortex in man. J Physiol 477:223-235. Medline

Davidson AG, Buford JA (2006) Bilateral actions of the reticulospinal tract on arm and shoulder muscles in the monkey: stimulus triggered averaging. Exp Brain Res 173:25-39. CrossRef Medline

Davidson AG, Schieber MH, Buford JA (2007) Bilateral spike-triggered average effects in arm and shoulder muscles from the monkey pontomedullary reticular formation. J Neurosci 27:8053-8058. CrossRef Medline

de Jong PT, de Jong JM, Cohen B, Jongkees LB (1977) Ataxia and nystagmus induced by injection of local anesthetics in the Neck. Ann Neurol 1:240 246. CrossRef Medline

Dewald JP, Pope PS, Given JD, Buchanan TS, Rymer WZ (1995) Abnormal muscle coactivation patterns during isometric torque generation at the elbow and shoulder in hemiparetic subjects. Brain 118:495-510. Medline

Edney DP, Porter JD (1986) Neck muscle afferent projections to the brainstem of the monkey: implications for the neural control of gaze. J Comp Neurol 250:389-398. CrossRef Medline

Ellis MD, Drogos J, Carmona C, Keller T, Dewald JP (2012) Neck rotation modulates flexion synergy torques, indicating an ipsilateral reticulospinal source for impairment in stroke. J Neurophysiol 108:3096-3104. CrossRef Medline

Farmer SF, Ingram DA, Stephens JA (1990) Mirror movement studied in a patient with Klippel-Feil syndrome. J Physiol 428:467-484. Medline

Farmer SF, Harrison LM, Ingram DA, Stephens JA (1991) Plasticity of central motor pathways in children with hemiplegic cerebral palsy. Neurology 41:1505-1510. CrossRef Medline

Fukuda T (1961) Studies on human dynamic postures from the viewpoint of postural reflexes. Acta Otolaryngol Suppl 161:1-52. Medline

Fukushima K (1997) Corticovestibular interactions: anatomy, electrophysiology, and functional considerations. Exp Brain Res 117:1-16. CrossRef Medline

Gandevia SC (2001) Spinal and supraspinal factors in human muscle fatigue. Physiol Rev 81:1725-1789. Medline

Ganguly K, Secundo L, Ranade G, Orsborn A, Chang EF, Dimitrov DF, Wallis JD, Barbaro NM, Knight RT, Carmena JM (2009) Cortical representation of ipsilateral arm movements in monkey and man. J Neurosci 29: 12948-12956. CrossRef Medline

Hellebrandt FA, Houtz SJ, Partridge MJ, Walters CE (1956) Tonic neck reflexes in exercises of stress in man. Am J Phys Med 35:144-159. Medline

Jankowska E, Edgley SA (2006) How can corticospinal tract neurons contribute to ipsilateral movements? A question with implications for recovery of motor functions. Neuroscientist 12:67-79. CrossRef Medline

Lacquaniti F, Maioli C, Fava E (1984) Cat posture on a tilted platform. Exp Brain Res 57:82-88. Medline

Le Pellec A, Maton B (1993) The influence of tonic neck reflexes on voluntary fatiguing elbow movements in humans. Eur J Appl Physiol Occup Physiol 67:231-238. CrossRef Medline

Lindsay KW, Roberts TD, Rosenberg JR (1976) Asymmetric tonic labyrinth reflexes and their interaction with neck reflexes in the decerebrate cat. J Physiol 261:583-601. Medline 
MacKinnon CD, Quartarone A, Rothwell JC (2004) Inter-hemispheric asymmetry of ipsilateral corticofugal projections to proximal muscles in humans. Exp Brain Res 157:225-233. Medline

Mayston MJ, Harrison LM, Quinton R, Stephens JA, Krams M, Bouloux PM (1997) Mirror movements in X-linked Kallmann's syndrome I. A neurophysiological study. Brain 120:1199-1216. CrossRef Medline

McCouch GP, Ling TH, Deering ID (1950) Location of receptors for tonic neck reflexes. Am J Med Sci 219:347. Medline

Netz J, Lammers T, Hömberg V (1997) Reorganization of motor output in the nonaffected hemisphere after stroke. Brain 120:1579-1686. CrossRef Medline

Perez MA, Butler JE, Taylor JL (2014) Modulation of transcallosal inhibition by bilateral activation of agonist and antagonist proximal arm muscles. J Neurophysiol 111:405-414. CrossRef Medline

Prevosto V, Graf W, Ugolini G (2011) Proprioceptive pathways to posterior parietal areas MIP and LIPv from the dorsal column nuclei and the postcentral somatosensory cortex. Eur J Neurosci 33:444-4460. CrossRef Medline

Rosenzweig ES, Brock JH, Culbertson MD, Lu P, Moseanko R, Edgerton VR, Havton LA, Tuszynski MH (2009) Extensive spinal decussation and bilateral termination of cervical corticospinal projections in Rhesus monkeys. J Comp Neurol 513:151-163. CrossRef Medline

Rothwell JC, Hallett M, Berardelli A, Eisen A, Rossini P, Paulus W (1999) Magnetic stimulation: motor evoked potentials. Electroencephalogr Clin Neurophysiol Suppl 52:97-103. Medline

Sakai K, Ugawa Y, Terao Y, Hanajima R, Furubayashi T, Kanazawa I (1997) Preferential activation of different I waves by transcranial magnetic stimulation with a figure-of-eight-shaped coil. Exp Brain Res 113:24-32. CrossRef Medline

Schepens B, Drew T (2006) Descending signals from the pontomedullary reticular formation are bilateral, asymmetric, and gated during reaching movements in the cat. J Neurophysiol 96:2229-2252. CrossRef Medline

Soteropoulos DS, Edgley SA, Baker SN (2011) Lack of evidence for direct corticospinal contributions to control of the ipsilateral forelimb in monkey. J Neurosci 31:11208-11219. CrossRef Medline

Stecina K, Jankowska E (2007) Uncrossed actions of feline corticospinal tract neurones on hindlimb motoneurones evoked via ipsilaterally descending pathways. J Physiol 580:119-132. CrossRef Medline
Strick PL, Kim CC (1978) Input to primate motor cortex from posterior parietal cortex (area 5). I. Demonstration by retrograde transport. Brain Res 157:325-330. CrossRef Medline

Sugiuchi Y, Kakei S, Izawa Y, Shinoda Y (2004) Functional synergies among neck muscles revealed by branching patterns of single long descending motor-tract axons. Prog Brain Res 143:411-421. CrossRef Medline

Tazoe T, Perez MA (2013) Speed-dependent contribution of callosal pathways to ipsilateral movements. J Neurosci 33:16178-16188. CrossRef Medline

Tazoe T, Sasada S, Sakamoto M, Komiyama T (2013) Modulation of interhemispheric interactions across symmetric and asymmetric bimanual force regulations. Eur J Neurosci 37:96-104. CrossRef Medline

Thuret S, Moon LD, Gage FH (2006) Therapeutic interventions after spinal cord injury. Nat Rev Neurosci 7:628-643. CrossRef Medline

Tokizane T, Murao M, Ogata T, Kondo T (1951) Electromyographic studies on tonic neck, lumbar and labyrinthine reflexes in normal persons. Jpn J Physiol 2:130-146. CrossRef Medline

Wassermann EM, Fuhr P, Cohen LG, Hallett M (1991) Effects of transcranial magnetic stimulation on ipsilateral muscles. Neurology 41:17951799. CrossRef Medline

Wassermann EM, Pascual-Leone A, Hallett M (1994) Cortical motor representation of the ipsilateral hand and arm. Exp Brain Res 100:121-132. Medline

Wilson VJ (1988) Convergence of neck and vestibular signals on spinal interneurons. Prog Brain Res 76:137-143. CrossRef Medline

Wilson VJ, Peterson BW (1981) Vestibulospinal and reticulospinal systems. In: Handbook of physiology, vol 2, the nervous system (Brookhart JM, Mountcastle VB, eds), pp 667-702. Bethesda, MD: The American Physiological Society.

Wilson VJ, Schor RH, Suzuki I, Park BR (1986) Spatial organization of neck and vestibular reflexes acting on the forelimbs of the decerebrate cat. J Neurophysiol 55:514-526. Medline

Ziemann U, Ishii K, Borgheresi A, Yaseen Z, Battaglia F, Hallett M, Cincotta M, Wassermann EM (1999) Dissociation of the pathways mediating ipsilateral and contralateral motor-evoked potentials in human hand and arm muscles. J Physiol 518:895-906. CrossRef Medline 